\title{
Antioxidant Therapies: A Potential Role in Perinatal Medicine
}

\author{
S.L. Miller ${ }^{a, b}$ E.M. Wallace ${ }^{a, b}$ D.W. Walker ${ }^{a, b}$ \\ ${ }^{a}$ The Ritchie Centre, Monash Institute of Medical Research, and ${ }^{b}$ Department of Obstetrics and Gynaecology, \\ Monash University, Clayton, Vic., Australia
}

\section{Key Words}

Antioxidant $\cdot$ Fetus $\cdot$ Neonate $\cdot$ Neuroprotection $\cdot$

Allopurinol $\cdot$ Melatonin $\cdot \alpha$-Lipoic acid $\cdot$ Vitamin C . Vitamin E

\begin{abstract}
Pregnancies complicated by impaired placentation, acute severe reductions in oxygen supply to the fetus, or intrauterine infection are associated with oxidative stress to the mother and developing baby. Such oxidative stress is characterized as an upregulation in the production of oxidative or nitrative free radicals and a concomitant decrease in the availability of antioxidant species, thereby creating a state of fetoplacental oxidative imbalance. Recently, there has been a good deal of interest in the potential for the use of antioxidant therapies in the perinatal period to protect the fetus, particularly the developing brain, against oxidative stress in complications of pregnancy and birth. This review will examine why the immature brain is particularly susceptible to oxidative imbalance and will provide discussion on antioxidant treatments currently receiving attention in the adult and perinatal literature - allopurinol, melatonin, $\alpha$-lipoic acid, and vitamins $C$ and $E$. In addition, we aim to address the interaction between oxidative stress and the fetal inflammatory response, an interaction that may be vital when proposing antioxidant or other neuroprotective strategies.
\end{abstract}

Copyright $\odot 2012$ S. Karger AG, Basel

\section{KARGER}

Fax +4161306 1234

E-Mail karger@karger.ch

www.karger.com
(C) 2012 S. Karger AG, Basel

$0028-3835 / 12 / 0961-0013 \$ 38.00 / 0$

Accessible online at:

www.karger.com/nen

\section{Introduction}

Pregnancy is a state of metabolic challenge, and as such even a normal, healthy pregnancy is a state of oxidative stress compared with non-pregnancy, and is a challenge to be met by the mother and her developing baby [ 1 , $2]$. Due to its high metabolic rate and level of mitochondrial activity, the placenta is a key source of this oxidative stress $[3,4]$. Fetal tissues, the brain in particular, are vulnerable to the effects of oxygen and nitrogen-based free radicals, and the idea that antioxidants may protect the fetus against oxidative stress, especially in late pregnancy, has recently been given much attention. This review will discuss our current understanding of the association between feto-placental hypoxia, oxidative stress and pathways leading to perinatal brain damage, and provide an overview of antioxidant strategies that may protect the developing brain from this type of injury.

Oxidative stress implies that the production of prooxidant free radical species exceeds the capacity of cells within an organ to neutralize or scavenge them. The capacity of placental antioxidant defenses to mitigate the effects of highly reactive and potentially damaging radicals is critical for healthy placental function and optimal growth and development of the fetus. However, whether because of variations in uteroplacental blood flow, or reduced placental function, or altered fetal demand, oxygen

\footnotetext{
Dr. Suzanne Miller

The Ritchie Centre, Monash Institute of Medical Research

27-31 Wright Street

Clayton, VIC 3168 (Australia)

Tel. +61 39902 4795, E-Mail suzie.miller@ monash.edu
} 
delivery to the placenta is relatively labile and a variety of fetal adaptations exist to allow the fetus to withstand acute or chronic reductions in oxygen availability. Nevertheless, the developing fetus may at times be exposed to high levels of oxidative stress due to overproduction of oxygen free radicals and a decrease in antioxidant defense capability.

Traditionally, it has been accepted that overproduction of reactive oxygen species and oxidative stress as a result of tissue hypoxia - caused by hypoxemia, hypoperfusion, and/or ischemia-reperfusion - follow a relatively simple and well-described causal pathway leading to cell damage; accumulation of reactive oxygen species in tissues is associated with considerable lipid and protein peroxidation, and cell death via apoptotic or necrotic pathways $[5,6]$. However, it is also important to note that oxidative stress and proinflammatory processes are strongly related $[7,8]$. Upon activation, many cells in the immune system generate oxygen free radicals and, equally, overproduction of free radicals induces an inflammatory response. The developing fetal brain is extremely susceptible to free radical-induced damage and systemic inflammatory challenge, and therefore, in situations of low oxygen availability, the fetus may benefit from targeted antioxidant neuroprotective strategies.

\section{Free Radicals and Oxidative Stress}

Atoms are considered stable in their basal state; that is, when every electron in the outermost shell contains a complimentary, or paired, electron [9]. A free radical describes a molecular species with an unpaired electron in the outer shell which then renders it highly reactive and unstable [9]. Free radicals containing oxygen may be termed a reactive oxygen species. The three most commonly described reactive oxygen species are superoxide $\left(\mathrm{O}_{2}^{-} \cdot\right)$, hydroxyl radical $(\mathrm{OH} \cdot)$ and the non-radical hydrogen peroxide $\left(\mathrm{H}_{2} \mathrm{O}_{2}\right)$. Of these, superoxide is considered the primary reactive oxygen species, as it is produced directly when oxygen $\left(\mathrm{O}_{2}\right)$ acquires an additional electron, then giving rise to the secondary reactive oxygen species, $\mathrm{H}_{2} \mathrm{O}_{2}$ and $\mathrm{OH} \cdot[10]$. Under normal physiological conditions, oxidative reduction occurs continuously, whereby mitochondria consume oxygen and reduce it to water in a process achieved by cytochrome oxidase in the mitochondrial respiratory chain. The rate of formation of reactive oxygen species is dependent on the amount of oxygen flowing through the mitochondria at any given time. Superoxide anion and $\mathrm{H}_{2} \mathrm{O}_{2}$ are byproducts of this mito- chondrial aerobic metabolism, and the production of these reactive oxygen species under normal conditions is balanced by enzymatic and non-enzymatic cellular scavenging strategies. One such enzymatic defense is superoxide dismutase, which specifically processes superoxide to produce $\mathrm{H}_{2} \mathrm{O}_{2}$, which is then dissociated by catalase or glutathione peroxidase (GSHPx) into water and molecular oxygen. Additional small molecule antioxidants such as glutathione (GSH), ascorbic acid and tocopherol scavengers further mediate the detoxification of these free radicals [11]. The presence of $\mathrm{H}_{2} \mathrm{O}_{2}$ is uniquely challenging for tissues as it can be converted to the highly volatile and damaging $\mathrm{OH} \cdot$ in the presence of metal ions via the Fenton or Haber-Weiss reactions, or conversely, it may be catalysed, predominantly by GSHPx, and removed harmlessly as water [5].

Along with oxygen free radicals, nitric oxide (NO) complexes are also implicated in free radical injury. NO is a weak free radical overproduced by nitric oxide synthase under hypoxic conditions. NO is capable of rapidly combining with superoxide to form peroxynitrite, a potent free radical strongly implicated in compromise of cellular function due to lipid peroxidation [12].

At normal rates of cellular respiration, oxygen and nitrogen free radicals are involved in mediating certain physiological processes, including the intracellular regulation of calcium, activation of transcription factors and protein phosphorylation [reviewed in 10]. However, the accumulation of the reactive free radicals beyond the capacity for the endogenous antioxidant defense system to scavenge them results in damage to DNA, proteins and lipids that initially compromises cell function, and can ultimately lead to cell death via apoptosis or necrosis [13]. The overproduction of oxygen free radicals in response to altered oxygenation and/or reperfusion is severely detrimental to cells, particularly via lipid peroxidation. Lipid peroxidation describes a chain of reactions between free radicals and polyunsaturated lipids contained within biological membranes, producing membrane destruction [6]. Aldehydes such as malondialdehyde (MDA) and 4-hydroxyalkenals (including 4-hydroxynonenal; 4 -HNE) are by-products of the peroxidative degradation of polyunsaturated fatty acids, with tissue level concentrations commonly used to provide a convenient index of lipid peroxidation. Excessive production of MDA and 4-HNE further augments cell damage. In addition, lipid peroxidation triggers arachidonic acid metabolism by cyclooxygenase and lipoxygenase to produce bioactive eicosanoids such as prostaglandins, thromboxanes and leukotrienes [14]. 


\section{The Oxygen Environment in Pregnancy}

Sir Joseph Barcroft likened life in utero to living on Mount Everest. This is true in the sense that the partial pressure of oxygen is low, but not accurate in the sense that oxygen supply is limited. A number of fetal and placental adaptations are present from early pregnancy that ensure delivery of oxygen to tissues despite the low gaseous diffusing potential, including high fetal cardiac output, relative vasodilatation of the feto-placental vasculature, and a high oxygen-carrying capacity of fetal blood. Thus, while the fetus is 'hypoxic' relative to the adult, it is not 'hypoxaemic' in that, under normal circumstances, sufficient oxygen is always delivered to meet its requirements of metabolism and growth.

Nevertheless, reduction in fetal oxygenation is not an uncommon event in pregnancy, arising acutely from decreases in uterine or umbilical blood flow - for example during uterine contractions - or chronically when remodeling of the utero-placental circulation does not keep pace with the increased oxygen demand of the fetus as it grows. Chronic fetal hypoxemia, most commonly caused by placental insufficiency, produces an adaptive reduction of fetal growth; so-called intrauterine growth restriction (IUGR). In addition to chronic hypoxia and poor nutrient supply from a dysfunctional placenta, the IUGR fetus must cope with prolonged elevation of inflammatory products and oxygen free radicals arising from the dysfunctional placenta. Severe hypoxia, whether acute or chronic, is also likely to lead to oxidative stress, particularly when transient changes of perfusion or oxygenation leads to free radical production due to uncoupled electron flow in the mitochondrial electron transport chain $[9,13,15]$. While mitochondria are the major source of reactive oxygen species following hypoxia-ischemia, and in particular reperfusion $[14,16]$, free radical production via other oxidative and non-oxidative metabolic processes is also induced, such as through the xanthine/xanthine oxidase pathway, via NADPH oxidases, or by increased prostaglandin synthesis [17]. This is particularly pertinent in complications of pregnancy including preeclampsia and IUGR, where there is evidence of excessive activity in oxidative and nitrative stress pathways not balanced by a sufficient increase of cellular antioxidant capacity [18].

\section{Hypoxia and the Developing Brain}

There are a number of reasons that the developing brain may be more sensitive to oxidative stress and free radical attack than most other tissues. Some cell types in the developing fetal brain, particularly the immature oligodendrocytes, are extremely vulnerable to free radical injury and their loss may lead to irreversible injury such as white matter loss $[19,20]$. Further, the newborn brain has a relatively high oxygen requirement compared to the adult brain, suggesting a high basal production of reactive oxygen species. To compound this, the developing brain has a high concentration of lipids, primarily due to high polyunsaturated fatty-acid content, increasing its susceptibility to lipid peroxidation [19]. Last, relative to the adult brain the newborn brain has an underdeveloped and limited antioxidant defence capacity [21,22]. Therefore, not surprisingly, there is direct and indirect evidence that oxidative stress plays a central role in mediating developmental brain injury $[16,19,23]$. In late gestation fetal sheep, we have used umbilical cord occlusion to show that acute fetal asphyxia causes increased production of hydroxyl radical within the fetal brain, predominantly in the grey matter [24], and widespread upregulation of lipid peroxidation (4-HNE positive cells) in both the grey and white matter [25]. Our observations are supported by those of others where upregulation of free radicals and lipid peroxidation products within the brain following acute perinatal asphyxia has been shown to occur across a range of species and under varying experimental conditions [26-28]. In addition, we have shown that chronic fetal hypoxia induced by single umbilical artery ligation - which causes placental insufficiency and mimics human fetal IUGR - increased the level of lipid peroxidation in the fetal brain [29], with the hippocampus showing the greatest increase of 4-HNE immunopositive cells. This increase in oxidative stress was associated with increased apoptosis and cell death [29]. Importantly, with respect to any discussion of potential approaches to protecting the developing brain, oxidative stress is an early event in the cascade of brain injury [16]. This offers the promise that targeting the imbalance between free radical production and free radical scavenging during fetoplacental hypoxia may be a rewarding approach resulting in reduced brain injury.

The regional susceptibility of the brain to oxidative stress changes with development. Immature oligodendrocytes are extremely sensitive to free radicals, lipid peroxidation and cell death [30]. In particular, the precursor oligodendrocytes (pre-oligodendrocytes) and immature 
oligodendrocytes, which predominate in the human brain between approximately 23-32 weeks gestation, are observed to be particularly susceptible to hypoxia-ischemia and oxygen free radical-induced injury [30]. The susceptibility of pre- and immature oligodendrocytes is due to the immature antioxidant capacity of these cells and the accumulation of iron and cell-specific vulnerability to $\mathrm{E}_{2}$-isoprostanes [20,31]. It is the susceptibility of these cells to oxidative injury and loss that underlies the vulnerability of the preterm brain to periventricular white matter damage [32]. In contrast, mature glial cells are more resistant to oxidative stress when compared to neurons. Nevertheless, neurons contain only low levels of the antioxidant GSH [33]. Because their function requires stable plasma and subcellular membrane structure [14], neurons are susceptible to damage arising directly from free radicals and from the effects of protein and lipid peroxidation. Thus, antioxidant therapy would seem an attractive and targeted approach to neuroprotection in babies that have experienced hypoxia or asphyxia in the perinatal period $[21,23,34-36]$.

\section{Oxidative Stress and the Inflammatory Response}

It is now well accepted that oxidative stress, infection, and inflammation are closely linked. This is particularly true in pregnancy $[7,8]$. Reactive oxygen species can initiate an inflammatory response and, conversely, many proinflammatory mediators stimulate the generation of free radicals and subsequent oxidative stress. Of these mediators, the transcription factor nuclear factor $-\kappa \mathrm{B}$ $(\mathrm{NF}-\kappa \mathrm{B})$ is thought to be the key to this interaction. It is upregulated by mediators of both inflammation and by hypoxia itself [37]. In unstimulated cells, NF- $\kappa \mathrm{B}$ remains inactive within the cytoplasm, bound to the inhibitory protein IкB. A variety of proinflammatory signals, including cytokines, lipopolysaccharide and viruses induce the removal of I $\mathrm{KB}$ via phosphorylation, ubiquination and proteolysis. This dissociates NF- $\mathrm{KB}$ from its binding to I $\kappa \mathrm{B}$ and allows the migration of NF- $\kappa \mathrm{B}$ to the nucleus and activation of targeted gene transcription [37]. In addition, several lines of evidence now suggest a role for reactive oxygen species, particularly $\mathrm{H}_{2} \mathrm{O}_{2}$, as common and critical mediators for NF- $\kappa \mathrm{B}$ activation [37].

Intrauterine infection is often associated with fetal hypoxia, and although either direct fetal infection or the flooding of fetal tissues (in particular, the fetal brain) by proinflammatory cytokines is usually the point of discussion [38-40], the placenta itself shows considerable and distinct responses to infectious agents [41, 42]. Elevated ІкB phosphorylation and activation of NF- $\kappa$ B have been described in the placenta [42], and in turn, activated $\mathrm{NF}-\kappa \mathrm{B}$ mediates the production and release of placental proinflammatory cytokines such as interleukin- $1 \beta$ and tumour necrosis factor- $\alpha$ [42]. The predisposition of the placenta to generate free radicals and proinflammatory metabolites relates in part to the high placental content of the tryptophan-dependent enzyme indoleamine 2,3-dioxygenase (IDO). Indeed, the human placenta is documented as the tissue containing the highest amount of IDO (GeneAtlas U133A, 21009). IDO-dependent metabolism of tryptophan yields a number of kynurenine metabolites that are either proinflammatory in themselves, such as 3-OH anthranilic acid and picolinic acid, or excitotoxic by virtue of their actions at the NMDA receptor in the brain, such as quinolinic acid [43]. Increased levels of these cytotoxic tryptophan metabolites in human umbilical cord blood has been reported in association with signs of clinical infection [41]. It is likely that this is due to NF- $\kappa \mathrm{B}$ inducing the increase of tryptophan catabolism, as shown by a study using human placental explants [43]. In addition, the activation of NF- $\kappa \mathrm{B}$ can lead to release of reactive oxygen species, as shown by the fact that lipopolysaccharide-induced NF- $\mathrm{B}$ activation in fetal membranes was inhibited by pretreatment with the antiinflammatory agent sulfasalazine, with a concomitant decrease in proinflammatory cytokine release [44]. These observations show that the placenta itself is an important source of reactive free radicals, confirming previous reports by Myatt et al. $[3,18]$, and imply that treatments that either target or include the placenta may be necessary in devising successful neuroprotective strategies for the fetal and newborn brain.

\section{Potential Antioxidant Therapies to Target Oxidative Stress in Pregnancy}

It is a given that any proposal to protect the fetus by pretreatment of the mother must, in itself be benign, and impose no additional risk burden on either the mother or her baby. The substances discussed below have had their safety profiles sufficiently characterized to be considered as candidate therapies, but further rigorous testing in appropriate animal models may be needed before clinical trials can be recommended. To some extent, this has already been done for melatonin, allopurinol, and vitamins $\mathrm{C}$ and $\mathrm{E}$ for which clinical RCT data are now available or underway. Most commonly, both experimental and clin- 
ical studies have examined antioxidant treatments in situations of acute perinatal hypoxia, but there is a clear lack of clinical studies assessing treatments aimed at reducing the burden of chronic fetal hypoxia and IUGR, whether by antioxidant therapies or other therapies. The exception to this is the therapeutic administration of vitamin $\mathrm{C}$ and $\mathrm{E}$ for the prevention of preeclampsia, for which data are discussed below. With this in mind, the information detailed in this review of perinatal antioxidant treatments predominantly deals with clinical and experimental data related to conditions of acute fetal or neonatal hypoxia.

A further important point, particularly related to acute asphyxia at birth, is that any potential new treatment must be compatible with, or indeed provide additive benefit to hypothermia. Induced hypothermia is the only standard neuroprotective treatment currently used in infants with clinical signs of hypoxic ischemic encephalopathy. Hypothermia has been evaluated under conditions of whole body cooling or selective head cooling, commencing either during transport to the tertiary NICU or at the hospital [45]. However, hypothermia has a number of limitations. First, it improves long-term outcomes by only about $30 \%$, meaning that the majority of asphyxial injury is not improved. Second, at least at present, hypothermia has only been assessed adequately in term infants and so is not yet utilised in preterm asphyxiated infants leaving these babies without a therapy. Next, the therapeutic window for the commencement of hypothermia is narrow (within $6 \mathrm{~h}$ of birth), and commencement of cooling after this time is not effective [45]. Accordingly, it may be such that adjuvant antioxidant therapy may enhance the neuroprotective benefits of hypother$\mathrm{mia}$, and/or prolong the window of opportunity for treatment commencement. The converse may also be true that hypothermia may extend the therapeutic benefits of adjuvant therapies such as treatment with antioxidants.

\section{Allopurinol}

In response to hypoxia-ischemia and subsequent reperfusion, an important source of oxygen free radical production is via the conversion of hypoxanthine to xanthine and uric acid. Under normal conditions, hypoxanthine forms xanthine and uric acid in the presence of xanthine dehydrogenase, without generating free radicals. However, an alternative pathway is highly upregulated upon the reintroduction of oxygen into hypoxic-ischemic tissues, as occurs with reperfusion, with the enzyme xan-

Antioxidant Therapy in Perinatal

Medicine thine dehydrogenase converted to xanthine oxidase in the presence of high concentrations of cytosolic calcium [14]. In turn, xanthine oxidase metabolises hypoxanthine to uric acid, using oxygen as the electron acceptor, and in the process forms highly reactive superoxide anions. Allopurinol protects against oxidative stress primarily by inhibiting the activity of xanthine oxidase. However, it is also a scavenger of the hydroxyl free radical $[46,47]$.

Allopurinol, and its active metabolite oxypurinol, has been an antioxidant of interest in perinatal medicine for some time. Over 25 years ago, it was shown that allopurinol treatment of newborn preterm babies reduced mortality associated with respiratory distress syndrome, an effect thought to be mediated by a decrease in the production of superoxide radicals [48]. The findings of a later study by Russell and Cooke [49] were somewhat confounding, demonstrating that allopurinol treatment to preterm babies did not provide protection against the development of morbidities associated with prematurity, such as periventricular leukomalacia. Animal studies have provided both specific assessments of the neuroprotective capabilities of allopurinol and insight into the mechanisms of action that may confer protective benefits. In 7-day old rat pups, allopurinol decreases cerebral edema and protects against long-term hypoxic-ischemic brain injury when administered either prior to hypoxia or soon after resuscitation [50,51]. This is an important insight for clinical use because, of course, treatments would usually only be commenced after resuscitation of an asphyxiated newborn baby. Studies in newborn piglets exposed to hypoxia demonstrate that allopurinol pretreatment successfully inhibits xanthine oxidase, increases cerebral levels of adenosine and also prevents asphyxia-induced NMDA receptor modification, thereby attenuating excitotoxicity $[52,53]$. The finding that allopurinol enhances brain adenosine is interesting given that adenosine is a neuromodulator in its own right, decreasing glutamate excitotoxicity but also potentially decreasing normal oligodendrocytes maturational processes [54]. Allopurinol treatment of pregnant sheep reduces markers of oxidative stress in the fetal circulation in response to ischemia-reperfusion and returns umbilical blood flow to basal levels more quickly [55], suggesting a buffering effect in the fetal cardiovascular system which may in turn protect the fetal brain against an excess of free radicals and acute perturbations of cerebral blood flow.

Other animal studies have examined systemic fetal responses to acute hypoxia, with and without maternal allopurinol treatment. Derks et al. [55] showed in fetal 
sheep that maternal allopurinol administration, begun during repeated umbilical cord occlusion, reduced markers of fetal cardiac oxidative stress associated with the xanthine oxidase pathway and improved indices of fetal cardiovascular compromise, particularly umbilical blood flow, during and subsequent to the ischemic-reperfusion challenge. Moderating the fetal cardiovascular response to an ischemic-reperfusion challenge would have presumed beneficial implications for the developing brain during such compromise.

Built on the experimental work, more recent human studies have examined the efficacy of allopurinol in protecting the fetal or neonatal brain against hypoxic events. High dose allopurinol administered to asphyxiated infants within $4 \mathrm{~h}$ after birth was shown to decrease systemic markers of oxidative stress and preserved cerebral blood volume and electrocortical brain activity [56]. In addition, infants treated with allopurinol after birth asphyxia had improved neurological and neurodevelopmental outcomes after 1 year [57]. A recent RCT followup by the Dutch group finds that overall there is no reduction in mortality or long-term neurodevelopmental disability in allopurinol versus placebo groups treated after birth asphyxia, however, subgroup analysis showed that allopurinol treatment may protect and improve outcomes in babies that had been exposed to moderate asphyxia, but not severe asphyxia [58]. The ALLO trial is currently underway in which allopurinol is administered to women carrying a term fetus at risk of intrauterine hypoxia [59], such that allopurinol will be administered before the onset of an acute insult. However, preliminary results from a small number of patients suggest that it has been difficult to achieve therapeutic cord blood levels of allopurinol and oxypurinol in compromised pregnancies. Nevertheless, where therapeutic levels of allopurinol/oxypurinol were achieved, the babies did have lower levels of S100B [60], consistent with a possible neuroprotective effect.

\section{Melatonin}

Melatonin (5-methoxy- $\mathrm{N}$-acetyltryptamine) is produced primarily by the pineal gland, providing circadian and seasonal timing cues. Highest levels of synthesis and secretion of melatonin occur at night. In addition to timing cues, melatonin is also a potent antioxidant, both as a scavenger of oxygen free radicals, particularly the highly destructive hydroxyl radical $[61,62]$, and indirectly via upregulation of the antioxidant enzymes GSHPx, GSH- reductase, superoxide dismutase and catalase $[61,62]$. As a treatment for use pregnancy or the neonatal period, melatonin has a number of attractive attributes. It readily crosses the placenta [24] and the blood-brain barrier [28], and has a good safety profile with no known adverse effects $[21,63]$. Several lines of evidence suggest that melatonin may be an effective neuroprotectant when given shortly before or after birth. Acute in utero asphyxia in the late-gestation fetal sheep results in a significant biphasic increase in hydroxyl radical formation within the grey matter of the fetal brain, consistent with primary and secondary phase oxidative stress. When melatonin is administered as prophylaxis to the ewe, both the primary and secondary increases in hydroxyl radical are abolished [24]. A rise in lipid peroxidation products and cerebral injury are also prevented with the pre-insult administration of melatonin $[24,28,64]$. The modulatory and neuroprotective actions of melatonin may not be solely due to the scavenging of hydroxyl radicals [24] and increasing intracerebral antioxidant enzyme activity [65]. Melatonin directly inhibits noradrenalin-stimulated fetal cerebral artery contraction [66], and decreases cerebral vascular permeability following hypoxia [67]. Systemically, melatonin induces umbilical vasodilatation via the stimulation of nitric oxide synthase [68], which may prove a particularly useful property in pregnancies complicated by placental insufficiency. Melatonin also has both pro- and anti-inflammatory actions, including activation of proinflammatory cytokines in the early phase response and mediating leukocyte recruitment [69]. An anti-inflammatory property of melatonin arises from the fact that it prevents the translocation of NFкB to the nucleus, thus reducing the upregulation of proinflammatory cytokines [62]. In response to acute fetal asphyxia, melatonin reduces inflammatory markers and cell death within the fetal sheep brain [28]. A small randomized trial of 20 babies with birth asphyxia has demonstrated that melatonin significantly reduces circulating levels of malondialdehyde and nitrate/nitrite compared to placebo [63]. Although this is a small study with only limited outcome measures - including no information on brain injury - it does provide proof-of-principle that melatonin can effectively reduce asphyxia-related oxidative and nitrative stress in newborns without apparent harm to the baby. A dose finding clinical trial is now underway in the UK to determine the appropriate dosing and pharmacokinetic profile of melatonin administration to preterm infants and to examine whether melatonin reduces brain injury related to prematurity. We are not aware of published clinical studies in which melatonin has been ad- 
ministered during the course of pregnancy, however, with this protective strategy in mind, it should be noted that animal data documents conflicting evidence of fetal endocrine modulation in response to exogenous melatonin. Sadowky et al. [70] found that melatonin administration to pregnant sheep resulted in a significant decrease in fetal plasma prostaglandin $\mathrm{E}_{2}$ via inhibition of prostaglandin synthase. However, we were not able to replicate this result, finding no effect on fetal plasma prostaglandin $E_{2}$ concentrations following a short, high-dose melatonin given to pregnant sheep [24]. It has also been shown that melatonin acts as a trophic factor on the fetal adrenal gland, acting to promote growth but reducing ACTH-induced cortisol production [71].

\section{$\alpha$-Lipoic Acid}

There is an established literature in adult models of hypoxia-ischemia to show that $\alpha$-lipoic acid has neuroprotective actions. $\alpha$-Lipoic acid (or thioctic acid) is present in human cells where it is a cofactor in mitochondrial dehydrogenase complexes [72]. In addition, it is considered to be a powerful antioxidant (often called the 'ultimate antioxidant') owing to its diverse range of actions in regulating oxidative stress pathways, its low molecular weight, and its ability to cross biological membranes including the blood-brain barrier. As an antioxidant compound, $\alpha$-lipoic acid scavenges oxygen free radicals (particularly hydroxyl radical), it chelates transition metals, and promotes the regeneration of endogenous antioxidants including vitamin $\mathrm{C}$ and $\mathrm{E}$ [73]. It also upregulates synthesis of GSHPx and modulates NF- $\kappa \mathrm{B}$ transcription to decrease NF- $\kappa \mathrm{B}$ activation, thereby acting in an antiinflammatory capacity $[72,73]$. Both $\alpha$-lipoic acid and its reduced form dihydrolipoate have similar antioxidant actions, although dihydrolipoate may be more potent since, in addition to hydrogen peroxide, it also scavenges superoxide radical and peroxyl radicals [73]. However, to date, many more studies have investigated the antioxidant and neuroprotective properties of $\alpha$-lipoic acid.

With diverse antioxidant properties, it is not surprising that $\alpha$-lipoic acid has protective effects for the adult brain against many insults that arise from overproduction of oxygen free radicals. In rat models of spinal cord injury [74] or subarachnoid hemorrhage [75], $\alpha$-lipoic acid administered post-insult significantly ameliorates the local increase in malondialdehyde and improves GSH levels, while reducing DNA damage. Administration of $\alpha$-lipoic acid to rats immediately prior to ischemia pre-

Antioxidant Therapy in Perinatal

Medicine vented the loss of GSH and profoundly decreased the mortality subsequent to ischemia-reperfusion [76]. Similarly, pretreating adult gerbils for 7 days with $\alpha$-lipoic acid protects against the oxidative damage associated with cerebral ischemia-reperfusion [77]. There are also a large number of studies that have investigated the potential benefits of $\alpha$-lipoic acid treatment in diabetes, since many of the complications associated with this disease are thought to be mediated by oxygen free radicals; in this capacity, $\alpha$-lipoic acid is able to increase insulin sensitivity and enhance glucose uptake [78]. With this therapeutic interest in mind, $\alpha$-lipoic acid has been given to pregnant diabetic mice and found to reduce the incidence of neural tube defects, and cardiovascular and skeletal malformations in offspring at term [79].

Despite these antioxidant actions, the neuroprotective actions of $\alpha$-lipoic acid are complicated by an efficacy that is very sensitive to dose, timing and route of administration. In focal cerebral ischemia in rats and mice, $\alpha$ lipoic acid was neuroprotective when administered subcutaneously, but not via other routes [80]. In the same study, it was shown that both $\alpha$-lipoic acid and dihydrolipoate were protective when administered subcutaneously $2 \mathrm{~h}$ prior to middle cerebral artery occlusion, but not when administered $1 \mathrm{~h}$ prior to the insult. The authors suggest that this finding reflected the time required for $\alpha$-lipoic acid to be reduced to dihydrolipoate [80]. In neonatal rats, Sheldon et al. [81] found that $\alpha$-lipoic acid prevented the loss of GSH after hypoxia-ischemia, but also resulted in significant mortality at higher doses, although they were not able to identify the cause of death. These rodent studies show that $\alpha$-lipoic acid has many and varied antioxidant and neuroprotective benefits, however, its use in pregnancy or with newborn animals requires further study, particularly in relation to whether it can be safely administered to the immature brain without altering normal developmental events. In addition, the timing of the hypoxic or ischemic insult would need to be appropriately diagnosed given that the timing of $\alpha$ lipoic acid treatment is crucial to its actions.

\section{Vitamins $C$ and $E$}

Vitamins $\mathrm{C}$ and $\mathrm{E}$ are essential nutrients and considered the most important antioxidants obtained through the diet. The antioxidant actions of vitamin $\mathrm{E}$ (the tocopherols and tocotrienols) lie in their ability to become incorporated into biological membranes to stabilise and protect against lipid peroxidation [82], while the antioxi- 
dant properties of vitamin $\mathrm{C}$ (ascorbic acid) arise because vitamin $\mathrm{C}$ acts as an electron donor, thereby preventing other agents from becoming oxidised and quenching an overproduction of free radicals. The literature pertaining to neuroprotective benefits of vitamins $\mathrm{C}$ and $\mathrm{E}$ in the perinatal period is limited, but in vitro evidence suggests that, in adult and fetal rat brain cultures, $\alpha$-tocopherol decreases lipid peroxidation and increases neuronal survival $[83,84]$. In vivo, prophylactic administration of ascorbic acid immediately prior to hypoxia-ischemia is able to decrease the numbers of apoptotic and necrotic cells within the fetal brain, although this treatment does not decrease markers of free radical production [85]. On a cautionary note, while vitamin $\mathrm{E}$ (as either $\alpha$-tocopherol or $\gamma$-tocotrienol) reduced the cell death induced by hydrogen peroxide, in the absence of oxidative stress, vitamin $\mathrm{E}$ independently induced apoptosis suggesting that it is protective only in the presence of oxidative stress [86]. If these findings were translated to clinical situations, it would be inappropriate to use vitamin $\mathrm{E}$ to prospectively protect the fetus or neonate against the effects of oxidative stress, limiting its use only in treating established oxidative stress. This would be impractical. However, $\alpha$-tocopherol has also been shown to have anti-inflammatory properties. Administration of $\alpha$-tocopherol, particularly in large doses, has been shown to decrease release of proinflammatory cytokines from cell lines exposed to lipopolysaccharide [87]. Furthermore, vitamin $\mathrm{E}$ is a potent microglial mitogen that may mediate the response to acute injury, an effect that is not dependent on its antioxidant properties [88]. It may be that the combination of vitamins $\mathrm{C}$ and $\mathrm{E}$ together is more effective, as when vitamin $\mathrm{E}$ is oxidised it forms $\alpha$-tocopherol radical which is harmful, but vitamin $\mathrm{C}$ is able to mediate the return of $\alpha$-tocopherol radical to $\alpha$-tocopherol, and thus regenerate $\alpha$-tocopherol concentrations in plasma [89]. In support of this, a study of transient intrauterine ischemia in pregnant rats showed that either vitamin $\mathrm{E}$ or vitamin $\mathrm{C}$ alone were able to decrease oxidative mitochondrial dysfunction in the fetal brain, but improvement was greatest when the vitamins were administered together [90].

There has been considerable interest in the efficacy of vitamins $\mathrm{C}$ and $\mathrm{E}$ supplementation in human pregnancy to assess whether complications such as preeclampsia, a condition strongly associated with maternal, placental and fetal oxidative stress, are improved with antioxidant treatments. Markers of oxidative stress and placental dysfunction are significantly reduced in the maternal circulation following supplementation of vitamins $\mathrm{C}$ and $\mathrm{E}$ [91]. An early trial also showed that administration of vi- tamins $\mathrm{C}$ and $\mathrm{E}$ in the second half of pregnancy, to women at risk of preeclampsia, significantly decreases biochemical markers of preeclampsia, and decreases the proportion of women who develop the disease when compared to placebo-treated at-risk women [92]. However, the most recent and largest trial to date demonstrates that there is no difference in the rates of preeclampsia in women taking antioxidant vitamin supplements, nor were there any differences in any of the maternal, fetal or neonatal complications measured [93]. This is confirmed in a recently published meta-analysis of vitamin $\mathrm{C}$ and $\mathrm{E}$ therapy for the prevention of preeclampsia, which found that combined vitamin treatment did not decrease the incidence of preeclampsia [94]. Indeed, vitamin $\mathrm{C}$ and $\mathrm{E}$ therapy may be associated with harm, increasing the risk of gestational hypertension and premature rupture of membranes [94]. Reassuringly, for those women treated with vitamin $\mathrm{C}$ and $\mathrm{E}$, there was no difference in adverse fetal or perinatal outcomes, although the authors note that no trials have yet reported longer-term follow-up of either mothers or children [94]. Accordingly, vitamin $\mathrm{C}$ and $\mathrm{E}$ trials have been abandoned, either preventative or therapeutic, in the management of preeclampsia and such therapy cannot be recommended for routine clinical practice.

\section{Summary}

There are now good data to demonstrate that an imbalance in pro- and antioxidant capacity in the developing brain occurs very early in the progress towards irreversible brain damage. This suggests that targeting the imbalance may be a rewarding neuroprotective approach. Indeed, both human and animal studies to date support that the administration of antioxidant compounds, such as those described here, effectively reduce fetal or neonatal brain injury following severe hypoxia or ischaemia. As such, these results suggest that overproduction of oxygen free radicals, and subsequent oxidative stress and lipid peroxidation, are key mediators in the progression of cerebral damage. However, the need to identify safe and effective therapies that can be delivered either during pregnancy or in the immediate post-birth period to protect the developing brain presents unique challenges. One challenge is the identification of high-risk babies and knowing when to target oxidative stress with an antioxidant therapy. Chronic hypoxia arising from placental insufficiency, or acute severe hypoxia-ischemia as occurs with birth asphyxia, are insults known to increase pro- 
duction of oxygen free radicals and produce perinatal brain injury and could potentially benefit from antioxidant therapies. However, as described above, each of the antioxidant substances have protective benefits that relate to the timing of administration with respect to both the insult event and the timing of the upregulation of oxidative pathways. Some compounds may confer protection only when administered prior to the hypoxic insult, while the efficacy of other antioxidants, particularly $\alpha$ lipoic acid, is dependent on the route and timing of administration. A cautionary observation is the finding that vitamin $\mathrm{E}$ is very effective in reducing cell death within the brain when hydrogen peroxide is upregulated by oxidative stress; however, when there is no pro-oxidant imbalance, vitamin E can induce apoptotic cell death directly. In addition, we should keep in mind that all of the compounds covered in this review mediate multiple physiological actions, in addition to their antioxidant abilities. This is particularly important with respect to the fetus and the immature brain, where developmental programming resulting from antenatal changes in endo- crine or cardiovascular function may have profound long-term effects. Both melatonin and allopurinol have vasoactive properties that may enhance their neuroprotective properties, but could also mediate cardiovascular development, maturation and long-term function. Furthermore, decreasing free radicals and restoring oxidative imbalance certainly appear to benefit the brain in response to episodes of hypoxia and reperfusion, but to date studies have not adequately addressed the consequences of altering oxidative or immune balance when there is no challenge present; that is, what happens when antioxidants are administered because oxidative stress is suspected, but in fact does not occur.

\section{Acknowledgements}

The authors wish to acknowledge funding support from NHMRC Australia, Cerebral Palsy Alliance Australia, and the Victorian Government's Operational Infrastructure Support Program.

\section{References}

1 Morris JM, Gopaul NK, Endresen MJ, 10 Buonocore G, Perrone S, Tataranno ML: OxKnight M, Linton EA, Dhir S, Anggard EE, Redman CW: Circulating markers of oxidative stress are raised in normal pregnancy and pre-eclampsia. Br J Obstet Gynaecol 1998;105:1195-1199.

2 Little RE, Gladen BC: Levels of lipid peroxides in uncomplicated pregnancy: a review of the literature. Reprod Toxicol 1999;13:347-352.

$\checkmark 3$ Myatt L, Cui X: Oxidative stress in the placenta. Histochem Cell Biol 2004;122:369382.

4 Walsh SW, Wang Y: Secretion of lipid peroxides by the human placenta. Am J Obstet Gynecol 1993;169:1462-1576.

5 Buonocore G, Perrone S, Tataranno ML: Oxygen toxicity: chemistry and biology of reactive oxygen species. Semin Fetal Neonatal Med 2010;15:186-190.

6 Lewen A, Matz P, Chan PH: Free radical pathways in CNS injury. J Neurotrauma 2000;17:871-890.

7 Hensley K, Robinson KA, Gabbita SP, Salsman S, Floyd RA: Reactive oxygen species, cell signaling, and cell injury. Free Radic Biol Med 2000;28:1456-1462.

$\checkmark 8$ Redman CW, Sargent IL: Pre-eclampsia, the placenta and the maternal systemic inflammatory respons - a review. Placenta 2003; 24(suppl A):S21- S27.

9 Floyd RA: Role of oxygen free radicals in carcinogenesis and brain ischemia. Faseb J 1990;4:2587-2597. ygen toxicity: chemistry and biology of reactive oxygen species. Semin Fetal Neonatal Med 2010;15:186-190.

11 Delivoria-Papadopoulos M, Mishra OP: Mechanisms of cerebral injury in perinatal asphyxia and strategies for prevention. J Pediatr 1998;132:S30-S34.

12 Rodrigo J, Fernandez AP, Serrano J, Peinado MA, Martinez A: The role of free radicals in cerebral hypoxia and ischemia. Free Radic Biol Med 2005;39:26-50.

13 Abramov AY, Scorziello A, Duchen MR: Three distinct mechanisms generate oxygen free radicals in neurons and contribute to cell death during anoxia and reoxygenation. J Neurosci 2007;27:1129-1138.

14 Traystman RJ, Kirsch JR, Koehler RC: Oxygen radical mechanisms of brain injury fol lowing ischemia and reperfusion. J Appl Physiol 1991;71:1185-1195.

15 Sugawara T, Chan PH: Reactive oxygen radicals and pathogenesis of neuronal death after cerebral ischemia. Antioxid Redox Signal 2003;5:597-607.

16 Blomgren K, Hagberg H: Free radicals, mitochondria, and hypoxia-ischemia in the developing brain. Free Radic Biol Med 2006;40: 388-397.

17 Vannucci RC, Perlman JM: Interventions for perinatal hypoxic-ischemic encephalopathy. Pediatrics 1997;100:1004-1014.
18 Myatt L: Placental adaptive responses and fetal programming. J Physiol 2006;572:2530.

19 Mishra OP, Delivoria-Papadopoulos M: Cellular mechanisms of hypoxic brain injury in the developing brain. Brain Res Bull 1999;48: 233-238.

20 Back SA: Perinatal white matter injury: the changing spectrum of pathology and emerging insights into pathogenetic mechanisms. Ment Retard Dev Disabil Res Rev 2006;12: 129-140.

21 Gitto E, Pellegrino S, Gitto P, Barberi I, Reiter RJ: Oxidative stress of the newborn in the pre- and postnatal period and the clinical utility of melatonin. J Pineal Res 2009;46: 128-139.

22 Saugstad OD: Mechanisms of tissue injury by oxygen radicals: implications for neonatal disease. Acta Paediatr 1996;85:1-4.

23 Volpe JJ: Perinatal brain injury: from pathogenesis to neuroprotection. Ment Retard Dev Disabil Res Rev 2001;7:56-64.

24 Miller SL, Yan EB, Castillo-Melendez M, Jenkin G, Walker DW: Melatonin provides neuroprotection in the late-gestation fetal sheep brain in response to umbilical cord occlusion. Dev Neurosci 2005;27:200-210.

25 Castillo-Melendez M, Chow JA, Walker DW: Lipid peroxidation, caspase-3 immunoreactivity, and pyknosis in late-gestation fetal sheep brain after umbilical cord occlusion. Pediatr Res 2004;55:864-871. 
-26 Bagenholm R, Nilsson UA, Kjellmer I: Formation of free radicals in hypoxic ischemic brain damage in the neonatal rat, assessed by an endogenous spin trap and lipid peroxidation. Brain Res 1997;773:132-138.

-27 Torres L, Anderson C, Marro P, Mishra OP, Delivoria-Papadopoulos M: Cyclooxygenase-mediated generation of free radicals during hypoxia in the cerebral cortex of newborn piglets. Neurochem Res 2004;29:18251830.

28 Welin AK, Svedin P, Lapatto R, Sultan B, Hagberg H, Gressens P, Kjellmer I, Mallard C: Melatonin reduces inflammation and cell death in white matter in the mid-gestation fetal sheep following umbilical cord occlusion. Pediatr Res 2007;61:153-158.

29 Miller SL, Chai M, Loose J, Castillo-Melendez M, Walker DW, Jenkin G, Wallace EM: The effects of maternal betamethasone administration on the intrauterine growth-restricted fetus. Endocrinology 2007; 148: 1288-1295.

- 30 Back SA, Gan X, Li Y, Rosenberg PA, Volpe JJ: Maturation-dependent vulnerability of oligodendrocytes to oxidative stress-induced death caused by glutathione depletion. J Neurosci 1998;18:6241-6253.

-31 Volpe JJ, Kinney HC, Jensen FE, Rosenberg PA: The developing oligodendrocyte: key cellular target in brain injury in the premature infant. Int J Dev Neurosci 2011;29:423440.

-32 Volpe JJ: Neurobiology of periventricular leukomalacia in the premature infant. Pediatr Res 2001;50:553-562.

-33 Dringen R: Metabolism and functions of glutathione in brain. Prog Neurobiol 2000;62: 649-671.

-34 Fatemi A, Wilson MA, Johnston MV: Hypoxic-ischemic encephalopathy in the term infant. Clin Perinatol 2009;36:835-858, vii.

35 Perlman JM: Intervention strategies for neonatal hypoxic-ischemic cerebral injury. Clin Ther 2006;28:1353-1365.

-36 van Bel F, Groenendaal F: Long-term pharmacologic neuroprotection after birth asphyxia: where do we stand? Neonatology 2008;94:203-210.

- 37 Li N, Karin M: Is NF-kappaB the sensor of oxidative stress? Faseb J 1999;13:1137-1143.

- 38 Hutton LC, Castillo-Melendez M, Smythe GA, Walker DW: Microglial activation, macrophage infiltration, and evidence of cell death in the fetal brain after uteroplacental administration of lipopolysaccharide in sheep in late gestation. Am J Obstet Gynecol 2008;198:117, e1-e11.

-39 Hutton LC, Castillo-Melendez M, Walker DW: Uteroplacental inflammation results in blood brain barrier breakdown, increased activated caspase 3 and lipid peroxidation in the late gestation ovine fetal cerebellum. Dev Neurosci 2007;29:341-354.

-40 Peebles DM, Miller S, Newman JP, Scott R, Hanson MA: The effect of systemic administration of lipopolysaccharide on cerebral haemodynamics and oxygenation in the 0.65 gestation ovine fetus in utero. Bjog 2003;110: 735-743.

41 Manuelpillai U, Ligam P, Smythe G, Wallace EM, Hirst J, Walker DW: Identification of kynurenine pathway enzyme mRNAs and metabolites in human placenta: up-regulation by inflammatory stimuli and with clinical infection. Am J Obstet Gynecol 2005; 192:280-288.

42 Cindrova-Davies T, Spasic-Boskovic O, Jauniaux E, Charnock-Jones DS, Burton GJ: Nuclear factor-kappa B, p38, and stress-activated protein kinase mitogen-activated protein kinase signaling pathways regulate proinflammatory cytokines and apoptosis in human placental explants in response to oxidative stress: effects of antioxidant vitamins. Am J Pathol 2007;170:1511-1520.

43 Dharane Nee Ligam P, Manuelpillai U, Wallace E, Walker DW: NFkappaB-dependent increase of kynurenine pathway activity in human placenta: inhibition by sulfasalazine. Placenta 2010;31:997-1002.

44 Lappas M, Permezel M, Georgiou HM, Rice GE: Nuclear factor kappa B regulation of proinflammatory cytokines in human gestational tissues in vitro. Biol Reprod 2002;67: 668-673.

45 Higgins RD, Raju T, Edwards AD, Azzopardi DV, Bose CL, Clark RH, Ferriero DM, Guillet R, Gunn AJ, Hagberg H, Hirtz D, Inder TE, Jacobs SE, Jenkins D, Juul S, Laptook AR, Lucey JF, Maze M, Palmer C, Papile L, Pfister RH, Robertson NJ, Rutherford M, Shankaran S, Silverstein FS, Soll RF, Thoresen M, Walsh WF: Hypothermia and other treatment options for neonatal encephalopathy: an executive summary of the Eunice Kennedy Shriver NICHD workshop. J Pediatr 2011;159:851-858, e1.

-46 Moorhouse PC, Grootveld M, Halliwell B, Quinlan JG, Gutteridge JM: Allopurinol and oxypurinol are hydroxyl radical scavengers. FEBS Lett 1987;213:23-28.

47 Saugstad OD: Role of xanthine oxidase and its inhibitor in hypoxia: reoxygenation injury. Pediatrics 1996;98:103-107.

48 Boda D, Nemeth I, Hencz P, Denes K: Effect of allopurinol treatment in premature infants with idiopathic respiratory distress syndrome. Dev Pharmacol Ther 1984;7:357367.

49 Russell GA, Cooke RW: Randomised controlled trial of allopurinol prophylaxis in very preterm infants. Arch Dis Child Fetal Neonatal Ed 1995;73:F27-F31.

50 Palmer C, Towfighi J, Roberts RL, Heitjan DF: Allopurinol administered after inducing hypoxia-ischemia reduces brain injury in 7-day-old rats. Pediatr Res 1993;33:405-411.

51 Palmer C, Vannucci RC, Towfighi J: Reduction of perinatal hypoxic-ischemic brain damage with allopurinol. Pediatr Res 1990; 27:332-336

52 Marro PJ, Mishra OP, Delivoria-Papadopoulos M: Effect of allopurinol on brain adeno- sine levels during hypoxia in newborn piglets. Brain Res 2006;1073-1074:444-450.

-53 Marro PJ, Hoffman D, Schneiderman R, Mishra OP, Delivoria-Papadopoulos M: Effect of allopurinol on NMDA receptor modification following recurrent asphyxia in newborn piglets. Brain Res 1998;787:71-77.

54 Rivkees SA, Wendler CC: Adverse and protective influences of adenosine on the newborn and embryo: implications for preterm white matter injury and embryo protection. Pediatr Res 2011;69:271-278.

55 Derks JB, Oudijk MA, Torrance HL, Rademaker CM, Benders MJ, Rosen KG, Cindrova-Davies T, Thakor AS, Visser GH, Burton GJ, van Bel F, Giussani DA: Allopurinol reduces oxidative stress in the ovine fetal cardiovascular system after repeated episodes of ischemia-reperfusion. Pediatr Res 2010; 68:374-380.

56 Van Bel F, Shadid M, Moison RM, Dorrepaal CA, Fontijn J, Monteiro L, Van De Bor M, Berger HM: Effect of allopurinol on postasphyxial free radical formation, cerebral hemodynamics, and electrical brain activity. Pediatrics 1998;101:185-193.

- 57 Gunes T, Ozturk MA, Koklu E, Kose K, Gunes I: Effect of allopurinol supplementation on nitric oxide levels in asphyxiated newborns. Pediatr Neurol 2007;36:17-24.

58 Kaandorp JJ, van Bel F, Veen S, Derks JB, Groenendaal F, Rijken M, Roze E, Venema MM, Rademaker CM, Bos AF, Benders MJ: Long-term neuroprotective effects of allopurinol after moderate perinatal asphyxia: follow-up of two randomised controlled trials. Arch Dis Child Fetal Neonatal Ed 2011, Epub ahead of print.

59 Kaandorp JJ, Benders MJ, Rademaker CM, Torrance HL, Oudijk MA, de Haan TR, Bloemenkamp KW, Rijken M, van Pampus MG, Bos AF, Porath MM, Oetomo SB, Willekes C, Gavilanes AW, Wouters MG, van Elburg RM, Huisjes AJ, Bakker SC, van Meir CA, von Lindern J, Boon J, de Boer IP, Rijnders RJ, Jacobs CJ, Uiterwaal CS, Mol BW, Visser GH, van Bel F, Derks JB: Antenatal allopurinol for reduction of birth asphyxia induced brain damage (ALLO-Trial); a randomized double blind placebo controlled multicenter study. BMC Pregnancy Childbirth 2010;10:8.

-60 Torrance HL, Benders MJ, Derks JB, Rademaker CM, Bos AF, Van Den Berg P, Longini $\mathrm{M}$, Buonocore $\mathrm{G}$, Venegas $\mathrm{M}$, Baquero $\mathrm{H}$, Visser GH, Van Bel F: Maternal allopurinol during fetal hypoxia lowers cord blood levels of the brain injury marker S-100B. Pediatrics 2009;124:350-357.

61 Reiter RJ, Tan DX: Melatonin: a novel protective agent against oxidative injury of the ischemic/reperfused heart. Cardiovasc Res 2003;58:10-19.

62 Reiter RJ, Tan DX, Osuna C, Gitto E: Actions of melatonin in the reduction of oxidative stress. A review. J Biomed Sci 2000;7:444458 . 
-63 Fulia F, Gitto E, Cuzzocrea S, Reiter RJ, Dugo L, Gitto P, Barberi S, Cordaro S, Barberi I: Increased levels of malondialdehyde and nitrite/nitrate in the blood of asphyxiated newborns: reduction by melatonin. J Pineal Res 2001:31:343-349.

64 Watanabe K, Wakatsuki A, Shinohara K, Ikenoue N, Yokota K, Fukaya T: Maternally administered melatonin protects against ischemia and reperfusion-induced oxidative mitochondrial damage in premature fetal rat brain. J Pineal Res 2004;37:276-280.

-65 Okatani Y, Wakatsuki A, Kaneda C: Melatonin increases activities of glutathione peroxidase and superoxide dismutase in fetal rat brain. J Pineal Res 2000;28:89-96.

- 66 Torres-Farfan C, Valenzuela FJ, Mondaca M, Valenzuela GJ, Krause B, Herrera EA, Riquelme R, Llanos AJ, Seron-Ferre M: Evidence of a role for melatonin in fetal sheep physiology: direct actions of melatonin on fetal cerebral artery, brown adipose tissue and adrenal gland. J Physiol 2008;586:40174027.

-67 Kaur C, Sivakumar V, Ling EA: Melatonin protects periventricular white matter from damage due to hypoxia. J Pineal Res 2010;48: 185-193.

68 Thakor AS, Herrera EA, Seron-Ferre M, Giussani DA: Melatonin and vitamin C increase umbilical blood flow via nitric oxidedependent mechanisms. J Pineal Res 2010; 49:399-406.

-69 Radogna F, Diederich M, Ghibelli L: Melatonin: a pleiotropic molecule regulating inflammation. Biochem Pharmacol 2010;80: 1844-1852.

-70 Sadowsky DW, Yellon S, Mitchell MD, Nathanielsz PW: Lack of effect of melatonin on myometrial electromyographic activity in the pregnant sheep at 138-142 days gestation (term $=147$ days gestation). Endocrinology 1991;128:1812-1818.

-71 Torres-Farfan C, Richter HG, Germain AM, Valenzuela GJ, Campino C, Rojas-Garcia P, Forcelledo ML, Torrealba F, Seron-Ferre M: Maternal melatonin selectively inhibits cortisol production in the primate fetal adrenal gland. J Physiol 2004;554:841-856.

-72 Holmquist L, Stuchbury G, Berbaum K, Muscat S, Young S, Hager K, Engel J, Munch G: Lipoic acid as a novel treatment for Alzheimer's disease and related dementias. Pharmacol Ther 2007;113:154-164.

73 Packer L, Tritschler HJ, Wessel K: Neuroprotection by the metabolic antioxidant alphalipoic acid. Free Radic Biol Med 1997;22:359378.
74 Toklu HZ, Hakan T, Celik H, Biber N, Erzik C, Ogunc AV, Akakin D, Cikler E, Cetinel S, Ersahin M, Sener G: Neuroprotective effects of alpha-lipoic acid in experimental spinal cord injury in rats. J Spinal Cord Med 2010; 33:401-409.

75 Ersahin M, Toklu HZ, Cetinel S, Yuksel M, Erzik C, Berkman MZ, Yegen BC, Sener G: Alpha lipoic acid alleviates oxidative stress and preserves blood brain permeability in rats with subarachnoid hemorrhage. Neurochem Res 2010;35:418-428.

76 Panigrahi M, Sadguna Y, Shivakumar BR, Kolluri SV, Roy S, Packer L, Ravindranath V: alpha-Lipoic acid protects against reperfusion injury following cerebral ischemia in rats. Brain Res 1996;717:184-188.

77 Cao X, Phillis JW: The free radical scavenger, alpha-lipoic acid, protects against cerebral ischemia-reperfusion injury in gerbils. Free Radic Res 1995;23:365-370.

78 Singh U, Jialal I: Alpha-lipoic acid supplementation and diabetes. Nutr Rev 2008;66: 646-657.

79 Sugimura Y, Murase T, Kobayashi K, Oyama K, Hayasaka S, Kanou Y, Oiso Y, Murata Y: Alpha-lipoic acid reduces congenital malformations in the offspring of diabetic mice. Diabetes Metab Res Rev 2009;25:287-294.

80 Wolz P, Krieglstein J: Neuroprotective effects of alpha-lipoic acid and its enantiomers demonstrated in rodent models of focal cerebral ischemia. Neuropharmacology 1996;35: 369-375.

81 Sheldon RA, Christen S, Ferriero DM: Genetic and pharmacologic manipulation of oxidative stress after neonatal hypoxia-ischemia. Int J Dev Neurosci 2008;26:87-92.

82 Packer L, Weber SU, Rimbach G: Molecular aspects of alpha-tocotrienol antioxidant action and cell signalling. J Nutr 2001;131: 369S-373S

83 Halks-Miller M, Henderson M, Eng LF: Alpha tocopherol decreases lipid peroxidation, neuronal necrosis, and reactive gliosis in reaggregate cultures of fetal rat brain. J Neuropathol Exp Neurol 1986;45:471-484.

84 Osakada F, Hashino A, Kume T, Katsuki H, Kaneko S, Akaike A: Neuroprotective effects of alpha-tocopherol on oxidative stress in rat striatal cultures. Eur J Pharmacol 2003;465: $15-22$.
85 Miura S, Ishida-Nakajima W, Ishida A, Kawamura M, Ohmura A, Oguma R, Sato Y, Takahashi T: Ascorbic acid protects the newborn rat brain from hypoxic-ischemia. Brain Dev 2009;31:307-417.

86 Then SM, Mazlan M, Mat Top G, Wan Ngah WZ: Is vitamin $\mathrm{E}$ toxic to neuron cells? Cell Mol Neurobiol 2009;29:485-496.

87 van Tits LJ, Demacker PN, de Graaf J, HakLemmers HL, Stalenhoef AF: alpha-tocopherol supplementation decreases production of superoxide and cytokines by leukocytes ex vivo in both normolipidemic and hypertriglyceridemic individuals. Am J Clin Nutr 2000;71:458-464.

88 Flanary BE, Streit WJ: Alpha-tocopherol (vitamin E) induces rapid, nonsustained proliferation in cultured rat microglia. Glia 2006; 53:669-674.

89 Beyer RE: The role of ascorbate in antioxidant protection of biomembranes: interaction with vitamin $\mathrm{E}$ and coenzyme Q. J Bioenerg Biomembr 1994;26:349-358.

90 Nakai A, Shibazaki Y, Taniuchi Y, Oya A, Asakura H, Koshino T, Araki T: Vitamins ameliorate secondary mitochondrial failure in neonatal rat brain. Pediatr Neurol 2002; 27:30-35.

91 Chappell LC, Seed PT, Kelly FJ, Briley A, Hunt BJ, Charnock-Jones DS, Mallet A, Poston L: Vitamin C and E supplementation in women at risk of preeclampsia is associated with changes in indices of oxidative stress and placental function. Am J Obstet Gynecol 2002;187:777-784.

92 Chappell LC, Seed PT, Briley AL, Kelly FJ, Lee R, Hunt BJ, Parmar K, Bewley SJ, Shennan AH, Steer PJ, Poston L: Effect of antioxidants on the occurrence of pre-eclampsia in women at increased risk: a randomised trial. Lancet 1999;354:810-816.

93 Roberts JM, Myatt L, Spong CY, Thom EA, Hauth JC, Leveno KJ, Pearson GD, Wapner RJ, Varner MW, Thorp JM, Jr, Mercer BM, Peaceman AM, Ramin SM, Carpenter MW, Samuels P, Sciscione A, Harper M, Smith WJ, Saade G, Sorokin Y, Anderson GB: Vitamins $\mathrm{C}$ and $\mathrm{E}$ to prevent complications of pregnancy-associated hypertension. N Engl J Med 2010;362:1282-1291.

94 Conde-Agudelo A, Romero R, Kusanovic JP, Hassan SS: Supplementation with vitamins $\mathrm{C}$ and $\mathrm{E}$ during pregnancy for the prevention of preeclampsia and other adverse maternal and perinatal outcomes: a systematic review and metaanalysis. Am J Obstet Gynecol 2011;204:503, e1-e12. 